\title{
The Change in Low Cloud Cover in a Warmed Climate Inferred from AIRS, MODIS, and ERA-Interim $\mathscr{O}$
}

\author{
DANiel T. McCoy, Ryan EAstman, Dennis L. HARTMAnN, And Robert WoOd \\ Department of Atmospheric Sciences, University of Washington, Seattle, Washington
}

(Manuscript received 19 October 2015, in final form 18 January 2017)

\begin{abstract}
Decreases in subtropical low cloud cover (LCC) occur in climate model simulations of global warming. In this study 8-day-averaged observations from the Moderate Resolution Imaging Spectroradiometer (MODIS) and the Atmospheric Infrared Sounder (AIRS) spanning 2002-14 are combined with European Centre for Medium-Range Weather Forecasts (ECMWF) interim reanalysis to compute the dependence of the observed variability of LCC on various predictor variables. Large-scale thermodynamic and dynamic predictors of LCC are selected based on insight from large-eddy simulations (LESs) and observational analysis. It is found that increased estimated inversion strength (EIS) is associated with increased LCC. Drying of the free troposphere is associated with decreased LCC. Decreased LCC accompanies subsidence in regions of relatively low EIS; the opposite is found in regions of high EIS. Finally, it is found that increasing sea surface temperature (SST) leads to a decrease in LCC. These results are in keeping with previous studies of monthly and annual data. Based upon the observed response of LCC to natural variability of the control parameters, the change in LCC is estimated for an idealized warming scenario where SST increases by $1 \mathrm{~K}$ and EIS increases by $0.2 \mathrm{~K}$. For this change in EIS and SST the LCC is inferred to decrease by $0.5 \%-2.7 \%$ when the regression models are trained on data observed between $40^{\circ} \mathrm{S}$ and $40^{\circ} \mathrm{N}$ and by $1.1 \%-1.4 \%$ when trained on data from trade cumulusdominated regions. When the data used to train the regression model are restricted to stratocumulusdominated regions the change in LCC is highly uncertain and varies between $-1.6 \%$ and $+1.4 \%$, depending on the stratocumulus-dominated region used to train the regression model.
\end{abstract}

\section{Introduction}

Oceanic boundary layer cloud cover strongly affects reflected shortwave (SW) radiation and has relatively little effect on the outgoing longwave (LW), leading to a negative cloud radiative effect that significantly impacts Earth's radiative balance (Hartmann and Short 1980). The overall response of low clouds to warming is highly uncertain (Bony et al. 2006; Caldwell et al. 2013; Vial et al. 2013; Webb et al. 2013). Despite this uncertainty, a recurrent feature of global climate models (GCMs) is a positive SW cloud feedback across the subtropics due to a decrease in boundary layer cloud cover. This feature is corroborated by long-term trends in observed cloud

Supplemental information related to this paper is available at the Journals Online website: http://dx.doi.org/10.1175/ JCLI-D-15-0734.s1.

Corresponding author e-mail: Daniel T. McCoy, dtmccoy@atmos. uw.edu cover (Norris et al. 2016). The strength of this decrease varies greatly within the CMIP5 and CMIP3 model ensembles, however (Myers and Norris 2016; Zelinka et al. 2012, 2013). Consequently, this uncertainty in the cloud feedback leads to significant uncertainty in the change in temperature in response to radiative forcing, or equilibrium climate sensitivity (ECS) (Vial et al. 2013; Webb et al. 2006).

Because clouds depend on turbulent motions with scales much smaller than the GCM horizontal resolution, GCMs must assume that low cloud cover (LCC) is dependent on large-scale thermodynamic and dynamic parameters (Qu et al. 2014b, 2015; Quaas 2012). Here we quantify the dependence of observed subtropical cloud cover on various large-scale predictors utilizing the record afforded to us by remote sensing and reanalysis at 8-day-average time scales. Clouds respond to changes in their environment on a time scale of hours to a week, making this selection of time scale appropriate (Eastman et al. 2016; Jones et al. 2014; Mauger and Norris 2010). This approach offers a useful comparison to studies utilizing monthly to interannual time 
scales to study the covariance of LCC and thermodynamic and dynamic predictor variables (Myers and Norris 2013, 2015, 2016; Qu et al. 2015; Seethala et al. 2015). Our study corroborates the results of these studies. It also provides a useful contrast to these studies because it examines low cloud cover, as opposed to cloud radiative effect (Myers and Norris 2015, 2016), and examines shorter time scales than previous studies of cloud cover (Qu et al. 2015; Seethala et al. 2015), allowing a much greater data volume to be examined. Our study verifies the results of these analyses using the observational record at the time scale for which clouds respond to their environment.

In this study, as in previous studies, the prospect of using observations to measure the relationship of cloud properties to their environment is constrained by structural uncertainty. If the time and space scales of the observations are too small, the relationships that govern the response of LCC to anthropogenically forced change may not emerge clearly because 1) it takes some time for clouds to respond to large-scale forcing, especially in the boundary layer (Eastman et al. 2016; Jones et al. 2014; Klein et al. 1995; Mauger and Norris 2010), and 2) clouds and boundary layer properties are advected through space by the large-scale horizontal flow. These problems can be partly alleviated by using a Lagrangian analysis that follows the air in the boundary layer, but this only reveals that the boundary layer clouds are in a constant state of adjustment to the changing large-scale conditions and adapting to them (Eastman and Wood 2016). Therefore, even Lagrangian experiments cannot reveal the ideal of an equilibrium cloud response to large-scale forcing.

In this paper we use simple simultaneous correlations between large-scale dynamic and thermodynamic predictors and LCC. It should be noted that the variability associated with temporal lags and horizontal advection is present in our data, but it is not addressed in the regression analysis. We take the view that disequilibrium between large-scale forcing and cloud properties is a feature of the mean state of the climate and so do not consider this a weakness of the analysis but an aspect of the climate. The hypothesis we are using is that a large enough sample of the relationships between large-scale forcing and clouds will capture the underlying physical relationships between large-scale forcing and boundary layer clouds that govern the observed climatology of LCC. We regress over a large volume of data, we divide the data into different subsets to test the robustness to sample, and we test how well the resulting statistical relationships can reproduce the observations.

A second structural uncertainty in the analysis presented in this paper arises in applying the relationships derived from current observations to the case of climate change. We will take the relationships we derive from current observations and apply them to the changes in large-scale control variables that global warming simulations produce to see if the relationships derived from the present predict the same cloud changes that climate models predict in response to warming. It is not an unreasonable conceit to think that the relationships between LCC and large-scale meteorological controls have value in predicting the change in LCC as the climate changes. In GCMs the twentiethcentury relationships between LCC and large-scale meteorological controls are able to predict the twentyfirst-century change in LCC (Qu et al. 2014b, 2015), and careful analysis of the satellite era shows that long-term observations of cloud cover beginning in the 1980 s echo the most robust elements of the changes in cloud cover that GCMs predict (Norris et al. 2016). Despite these pieces of evidence we cannot validate the satellite record against some other period of forced variability, and thus this constitutes a structural uncertainty in our analysis.

The organization of this paper is as follows: In section 2a we discuss the observational and reanalysis datasets used to diagnose LCC dependence on predictor variables. In section $2 b$ we detail regression modeling of LCC in terms of predictor variables. In section $2 b(2)$ the regression models developed from subsets of the observational record are evaluated in their ability to reproduce the observational record in the $40^{\circ} \mathrm{S}-40^{\circ} \mathrm{N}$ region as a whole. In section $3 \mathrm{a}$ we will discuss robust elements of the dependence of LCC on thermodynamic and dynamic predictors that appear across subsets of the dataset. In section $3 \mathrm{~b}$ we estimate the change in LCC in a highly idealized warming scenario and compare this to the decrease in LCC inferred from other observational datasets and CMIP5 models.

\section{Methods}

\section{a. Data}

In this study we examine LCC averaged over 8-day periods during 2002-14. In this section we provide a general overview of the data we use to analyze the dependence of LCC on thermodynamic and dynamic predictor variables. The predictor variables considered are as follows: estimated inversion strength (EIS) (Wood and Bretherton 2006), wind speed at $10 \mathrm{~m}$ $(\mathrm{U} 10 \mathrm{~m})$, pressure velocity at $550 \mathrm{hPa}(\omega 550)$ as a measure of atmospheric subsidence, free-tropospheric $\mathrm{RH}$ (RHFT), and finally SST. These predictors are discussed in more detail in section $2 \mathrm{~b}$. These predictor variables 
TABLE 1 . Summary of the remote sensing and reanalysis data used in this study.

\begin{tabular}{ll}
\hline & \\
\hline U10m & ERA-Interim octet-averaged 10-m wind speed. \\
SST & ERA-Interim octet-averaged SST. \\
RHFT & AIRS RH octet-averaged and averaged over the 450-650-hPa pressure levels. \\
EIS & EIS calculated according to Wood and Bretherton (2006) using AIRS retrievals of thermodynamic properties. The \\
& near-surface RH forecast in the AIRS data was used instead of a constant value as in Wood and Bretherton (2006). \\
W550 & Subsidence at 550-hPa octet-averaged from ERA-Interim. \\
LCC & MODIS collection six 8-day CTP histogram for solar zenith angle less than $32^{\circ}$ is used to calculate low cloud cover \\
& (CTP $>680 \mathrm{hPa})$ using random overlap.
\end{tabular}

are collocated with measurements of LCC. LCC retrieval is paired with relevant collocated thermodynamic and dynamic properties. The dataset is restricted to oceans in the latitude band $40^{\circ} \mathrm{S}-40^{\circ} \mathrm{N}$. Further subsetting into regions is discussed in section $2 \mathrm{~b}$. We will now discuss the satellite instruments and reanalysis used to create these two datasets. A summary of the data used in this study is provided in Table 1.

\section{1) MODIS}

Moderate Resolution Imaging Spectroradiometer (MODIS) instruments ride on board both the Terra and Aqua platforms (Oreopoulos 2005; Platnick et al. 2003). We will use these instruments to study the dependence of cloud fraction on large-scale control variables.

Cloud cover is assumed to be randomly overlapped. Active remote sensing indicates that random overlap is a reasonable assumption outside of regions of deep convection and landmasses ( $\mathrm{Li}$ et al. 2015; McCoy et al. 2014). To calculate LCC we use the 8-day-averaged MODIS cloud-top pressure (CTP) histogram provided in the Aqua collection 6 dataset filtered for sensor zenith angles of less than $32^{\circ}$, which reduces bias in cloud fraction retrieval (Maddux et al. 2010). Low clouds are defined to have a CTP $>680 \mathrm{hPa}$. The randomly overlapped low cloud fraction is calculated as

$$
\mathrm{LCC}_{\text {RandomOverlap }}=\mathrm{CF}_{\mathrm{CTP}>680 \mathrm{hPa}} /\left(1-\mathrm{CF}_{\mathrm{CTP}<680 \mathrm{hPa}}\right) \text {, }
$$

where the cloud fraction (CF) with CTP less than $680 \mathrm{hPa}$ is the sum of the cloud fraction in CTP bins less than $680 \mathrm{hPa}$, and CF with CTP greater than 680 is the sum of the cloud fraction in CTP bins greater than $680 \mathrm{hPa}$.

We will now discuss the thermodynamic and dynamic datasets collocated with the retrieved LCC.

\section{2) AIRS}

The Atmospheric Infrared Sounder (AIRS) rides on board the Aqua platform. It is a grating infrared spectrometer, which provides a vertical profile of atmospheric thermodynamic properties (Aumann et al. 2003). In this study we use the 8 -day-averaged data from the AIRS collection 6 to describe free-tropospheric relative humidity. Geophysical retrievals are obtained after cloud clearing has identified cloud-free and broken cloud scenes (Susskind et al. 2003). Error due to cloud contamination has been substantially reduced in collection 6 (Susskind et al. 2014) but may still represent a source of error. Soundings of temperature and pressure as well as the surface pressure and relative humidity forecasts included in the AIRS data are used to calculate EIS (Wood and Bretherton 2006). The free troposphere is examined using 450-650-hPa pressure levels in the AIRS collection 6 dataset. Free-tropospheric $\mathrm{RH}$ is calculated as the mean $\mathrm{RH}$ in the 450- and 650-hPa levels.

\section{3) ERA-INTERIM}

In this study we use data from the European Centre for Medium-Range Weather Forecasts (ECMWF) interim reanalysis (ERA-Interim) (Dee et al. 2011) to examine several thermodynamic and dynamic predictors. The four-times-daily output from ERA-Interim is interpolated to the local overpass time for the Aqua satellite. The U10m and $\omega 550$ are used in conjunction with LCC from MODIS because no equivalent dynamical retrieval product is available from AIRS.

\section{b. Regression analysis}

The goal of our analysis is to create a multiple linear regression model of LCC as a function of a set of predictor variables, in keeping with previous studies (Myers and Norris 2015; Qu et al. 2015). As in previous studies, the relations derived from this regression model can then be used to understand how the evolution of various large-scale predictor variables in a warming climate should change LCC. This assumes that the current relationships between LCC and the various predictors hold in a warming climate.

As noted in previous studies, many of the predictor variables of LCC covary (Myers and Norris 2015). This is problematic in terms of creating a robust regression 
model of LCC. Most notably, EIS and sea surface temperature (SST) are substantially negatively correlated ( $r<-0.6)$ (Fig. 1). Additionally, it is interesting to note that EIS's relation to SST is well fit by a hyperbolic tangent, and this nonlinearity may further complicate disentangling these predictors. Overall, the covariability of EIS and SST is especially problematic because both increase in a warmed climate but have conflicting effects on LCC (Qu et al. 2014a,b, 2015; Webb et al. 2013). This makes the change in LCC in a warming climate strongly sensitive to the relative strength of the relationship between these predictors and the LCC. To help alleviate the problem of colinearity, the multiple regression model is created using partial least squares (de Jong 1993; Wold et al. 1984, 2001). The regression models were trained using data at $1^{\circ} \times 1^{\circ}$ spatial and 8-day temporal resolution. Each regression model of LCC was trained using EIS, SST, U10m, RHFT, and pressure velocity (subsidence) as predictor variables.

To examine the robustness of the regression models created in this study we subset our dataset into regions. We first examine the $40^{\circ} \mathrm{S}-40^{\circ} \mathrm{N}$ region to see how LCC depends on predictor variables without subsetting the data to capture a particular dynamical regime. This region is split into $20^{\circ}$-latitude bands to examine robustness. The data in each $20^{\circ}$-latitude band are used to create a regression model. The spread in the coefficients in regression models is used to evaluate robustness of our results.

In addition to the $40^{\circ} \mathrm{S}-40^{\circ} \mathrm{N}$ region split into $20^{\circ}$-latitude bands, we considered several subregions associated with specific dynamical regimes. The behavior of stratocumulus (Sc) clouds (Klein and Hartmann 1993) is examined by creating subsets of the dataset containing the five subtropical low cloud regions as identified in $\mathrm{Qu}$ et al. (2015). These regions are dominated by large stratocumulus decks that transition to trade cumulus $(\mathrm{TrCu})$. This subset of the data will be referred to as $\mathrm{TrCu}-\mathrm{Sc}$. A regression model is trained in each of the stratocumulus-dominated regions yielding a total of five regression models of LCC. Trade cumulus cloud behavior is examined by creating subsets of the dataset containing five large subtropical trade cumulus-dominated regions. This subset of the data will be referred to as $\mathrm{TrCu}$. Training regression models of LCC on the data from each of these regions yields an additional five regression models. In total there are 14 regression models of LCC as predicted by U10m, EIS, SST, RHFT, and pressure velocity (subsidence). The $\mathrm{TrCu}$ and $\mathrm{TrCu}-\mathrm{Sc}$ regions are shown in Fig. 2. All subsets of the data used to create regression models are listed in Table 2.

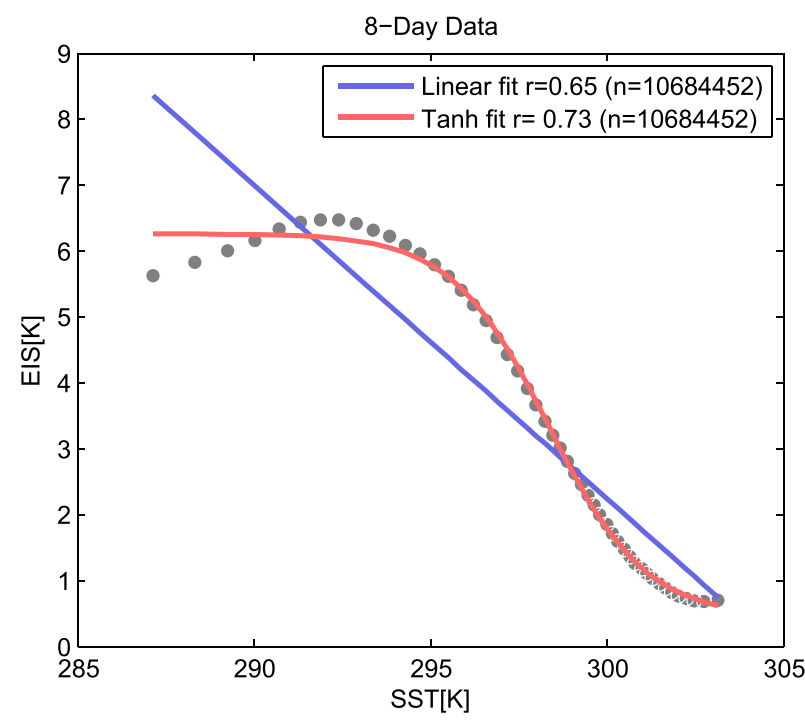

FIG. 1. EIS as a function of SST over the $40^{\circ} \mathrm{S}-40^{\circ} \mathrm{N}$ region. Binned values of EIS are shown as gray dots. Various fits to the data are shown in the legend with the correlation between the observed EIS and the predicted EIS based on the fit. The number of data points used to calculate the correlation is also noted.

\section{1) CHOICE OF PREDictor VARIABLES}

LCC exhibits considerable spatial variability across the subtropical oceans (Fig. 2). Although macrophysical and microphysical factors determine the coverage of low cloud (Albrecht 1989; Nakajima et al. 2001), in this study we consider only the relationship of low cloud to largescale thermodynamic and dynamic variables. This is problematic because correlation is not causation and cloud coverage and boundary layer properties affect each other. This issue is common to observational studies of the dependence of low cloud on atmospheric predictors (Eastman and Wood 2016; Klein and Hartmann 1993; Qu et al. 2015; Yue et al. 2013), and we acknowledge this issue. We provide the following arguments to support the view that the large-scale properties we have chosen have value as control variables. First, we refer to modeling analysis in support of mechanistic linkages between LCC and each predictor variable. Second, while clouds determine the boundary layer properties to some degree, we ameliorate this problem by selecting predictors of boundary layer properties that are somewhat more external to the boundary layer and are not as directly impacted by the cloud cover. That is to say, this work considers SST and wind speed, as opposed to air temperature and relative humidity within the boundary layer, although it might be argued that the latter variables more directly influence cloud cover. This being said, we cannot completely discount the possibility that relations between large-scale 


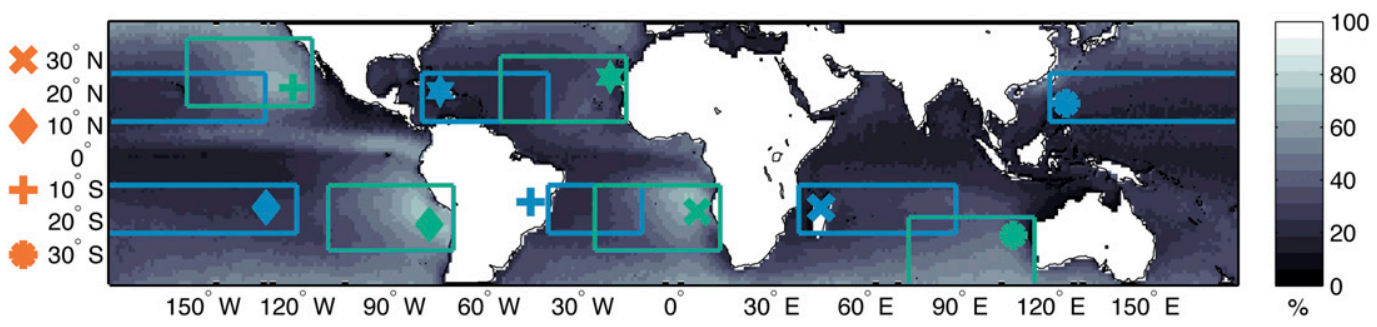

FIG. 2. The climatological LCC from MODIS from 8-day-averaged data. The regression model is trained using data from each of the $20^{\circ}$-latitude bands between $40^{\circ} \mathrm{S}$ and $40^{\circ} \mathrm{N}$ (orange symbols), each of the stratocumulusdominated regions that capture the TrCu-Sc transition (Qu et al. 2015) (shown in green), and each of the subtropical $\mathrm{TrCu}$ regimes (shown in blue). These regions are listed in Table 2. The colored symbols next to each region correspond to the symbol used in the remaining figures to denote that region.

predictors and LCC are correlative rather than causative. We will now discuss the predictor variables that we consider in this study and their anticipated effect on LCC.

Stronger inversions capping the planetary boundary layer (PBL) trap moisture more effectively, enhancing cloud fraction (Klein and Hartmann 1993; Wood and Bretherton 2006) and increasing its persistence (Eastman and Wood 2016). The importance of lowertropospheric stability (LTS) and subsequently EIS has been thoroughly established through numerous observational analyses (Klein and Hartmann 1993; Koshiro and Shiotani 2014; Myers and Norris 2013, 2015; Wood and Bretherton 2006). AIRS data describing atmospheric temperature, pressure, and near-surface RH and temperature are used to calculate EIS as detailed in Wood and Bretherton (2006), except that we use the observed near-surface $\mathrm{RH}$, as opposed to a constant value used in Wood and Bretherton (2006). A positive correlation between EIS and LCC is expected based on previous observational studies.

Modeling and observational studies indicate that as the subtropical free troposphere dries, in a relative sense, entrainment of warmer and drier air from the subtropical free troposphere leads to a thinning of low cloud by increasing the lifting condensation level more than the cloud-top height (Bretherton et al. 2013; Wood 2007, 2012), although thickening may occur for deep boundary layers and a free-tropospheric RH above $40 \%$ (Randall 1984). Coupling between free-tropospheric humidity and cloudiness is supported by large-eddy simulation (LES) and mixed-layer model (MLM) simulations (Bretherton et al. 2013; de Roode et al. 2014; van der Dussen et al. 2015).

LES studies indicate that decreasing subsidence allows cloud to thicken, although this seems to be regime and model dependent (Blossey et al. 2013; Bretherton et al. 2013). Observations indicate that EIS and subsidence are often correlated, but multiple linear regression and compositing show that EIS and subsidence have independent effects on LCC and that subsidence tends to reduce LCC at constant EIS (Myers and Norris 2013).

Because boundary layer relative humidity stays almost constant in a warming climate (Held and Soden 2000), early GCMs assumed clouds did not change as the climate warmed, and several years passed before cloud feedbacks became part of the scientific literature (Schneider 1972). Observational analysis of SST and stratiform cloud-cover anomalies show a robust negative relationship in the midlatitudes and eastern oceans (Clement et al. 2009; Eastman et al. 2011; Klein et al. 1995; Kubar et al. 2012; Norris and Leovy 1994). Singlecolumn and LES modeling robustly reduces cloudiness with warming in a constant relative humidity setting (Bretherton and Blossey 2014; Bretherton et al. 2013; Brient and Bony 2013; Rieck et al. 2012). Cloud thinning through increased surface temperature is examined by using SST as a predictor.

TABLE 2. Latitude and longitude ranges of the regional subsets analyzed in this study. These regions are shown in Fig. 2.

\begin{tabular}{ccc}
\hline \hline Region & Lat range & Lon range \\
\hline $40^{\circ} \mathrm{S}-40^{\circ} \mathrm{N}$ & $40^{\circ}-20^{\circ} \mathrm{S}$ & All longitudes \\
& $20^{\circ} \mathrm{S}-0^{\circ}$ & All longitudes \\
& $0^{\circ}-20^{\circ} \mathrm{N}$ & All longitudes \\
& $20^{\circ}-40^{\circ} \mathrm{N}$ & All longitudes \\
TrCu-Sc (Qu et al. 2015) & $10^{\circ}-30^{\circ} \mathrm{S}$ & $110^{\circ}-70^{\circ} \mathrm{W}$ \\
& $10^{\circ}-30^{\circ} \mathrm{S}$ & $25^{\circ} \mathrm{W}-15^{\circ} \mathrm{E}$ \\
& $20^{\circ}-40^{\circ} \mathrm{S}$ & $75^{\circ}-115^{\circ} \mathrm{E}$ \\
& $15^{\circ}-35^{\circ} \mathrm{N}$ & $155^{\circ}-115^{\circ} \mathrm{W}$ \\
& $10^{\circ}-30^{\circ} \mathrm{N}$ & $55^{\circ}-15^{\circ} \mathrm{W}$ \\
$\operatorname{TrCu}$ & $10^{\circ}-25^{\circ} \mathrm{S}$ & $180^{\circ}-120^{\circ} \mathrm{W}$ \\
& $10^{\circ}-25^{\circ} \mathrm{S}$ & $40^{\circ}-90^{\circ} \mathrm{E}$ \\
& $10^{\circ}-25^{\circ} \mathrm{S}$ & $40^{\circ}-10^{\circ} \mathrm{W}$ \\
& $10^{\circ}-25^{\circ} \mathrm{N}$ & $120^{\circ} \mathrm{E}-130^{\circ} \mathrm{W}$ \\
& $10^{\circ}-25^{\circ} \mathrm{N}$ & $80^{\circ}-40^{\circ} \mathrm{W}$ \\
\hline
\end{tabular}


r

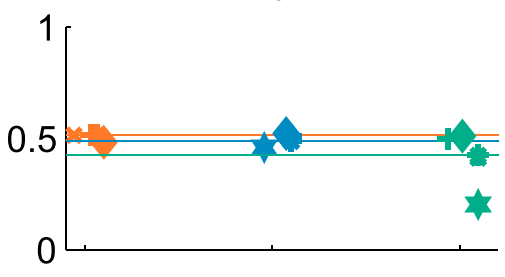

RMSE

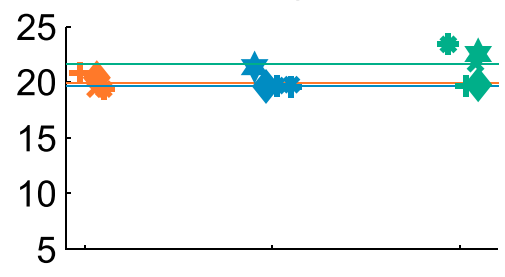

mean bias

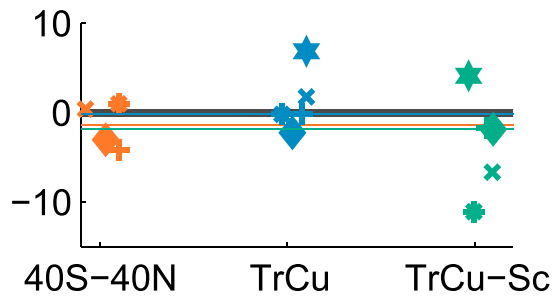

$r$ (Climatology)
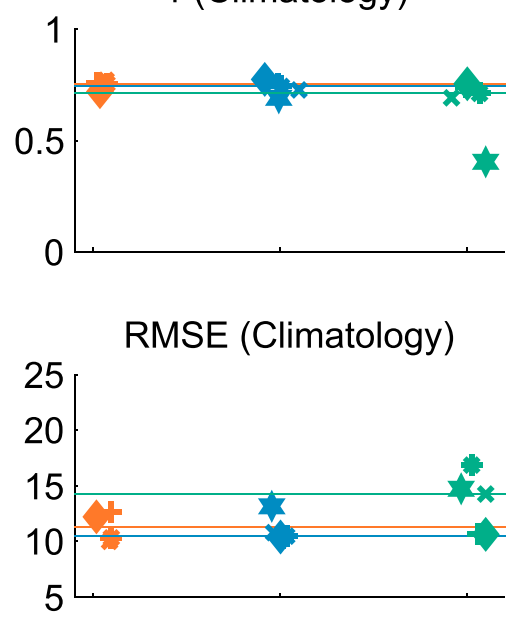

mean bias (Climatology)

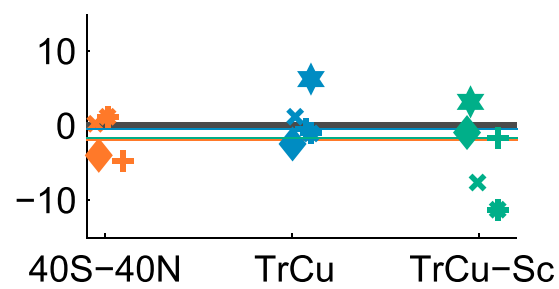

FIG. 3. (left) Evaluation of the ability of the regression models trained in each subregion to reproduce the observed LCC over $40^{\circ} \mathrm{S}-40^{\circ} \mathrm{N}$ at $1^{\circ} \times 1^{\circ}$ spatial resolution and 8-day temporal resolution and (right) when the observational record of LCC is averaged to create a 12-month climatology at $1^{\circ} \times 1^{\circ}$ spatial resolution. The regression models being evaluated are differentiated by region and subregion (see Fig. 2). The region used to train the regression model noted on the $x$ axis. Regression coefficients, RMSE, and mean-bias for the regression models trained in each of the subregions are shown as dots. Scatter along the $x$ axis has been added for visual clarity. The units of RMSE and mean bias are in units of percent cloud cover.

\section{2) ABILITY OF THE REGRESSION MODELS TO REPRODUCE OBSERVED LCC}

We evaluate the ability of the 14 regression models trained in different data subsets (one from each subregion listed in Table 2) to reproduce the observed temporal and spatial pattern of LCC. The historical LCC is calculated using each subregion's regression model and the observed predictor variables over the 2002-14 period and in the $40^{\circ} \mathrm{S}-40^{\circ} \mathrm{N}$ region. The following evaluations of the regression models from each subregion are performed: 1) How well can the regression model reproduce the historical record? 2) How well can the regression model reproduce the observed climatology? The first question is answered by evaluating the regression model trained in each subset of the data against the $40^{\circ} \mathrm{S}-40^{\circ} \mathrm{N}$ data at $1^{\circ} \times 1^{\circ}$ spatial resolution and 8-day temporal resolution for the years 2002 14. The second question is answered by averaging the dataset to create a climatology of 12 months at $1^{\circ} \times 1^{\circ}$ spatial resolution and then evaluating the regression model. Regression model performance was evaluated using RMSE, correlation, and the mean bias between observed and predicted LCC.

The correlation coefficient, root-mean-square error (RMSE), and mean bias between the observed and predicted LCC are shown in Fig. 3. The ranges of the correlation coefficient, RMSE, and mean bias in Fig. 3 show how much each quantity changes between the different regression models. For example, the range for the $\mathrm{TrCu}-\mathrm{Sc}$ regime is given by comparing the five regression models (one for each subregion). The LCC calculated from MODIS data and random overlap is not likely to be robust in the regions of deep convection. Therefore, regions where the climatological pressure velocity at $550 \mathrm{hPa}$ is closer to zero than $-0.005 \mathrm{~Pa} \mathrm{~s}^{-1}$ are excluded from the calculation of the correlation coefficient to prevent the 

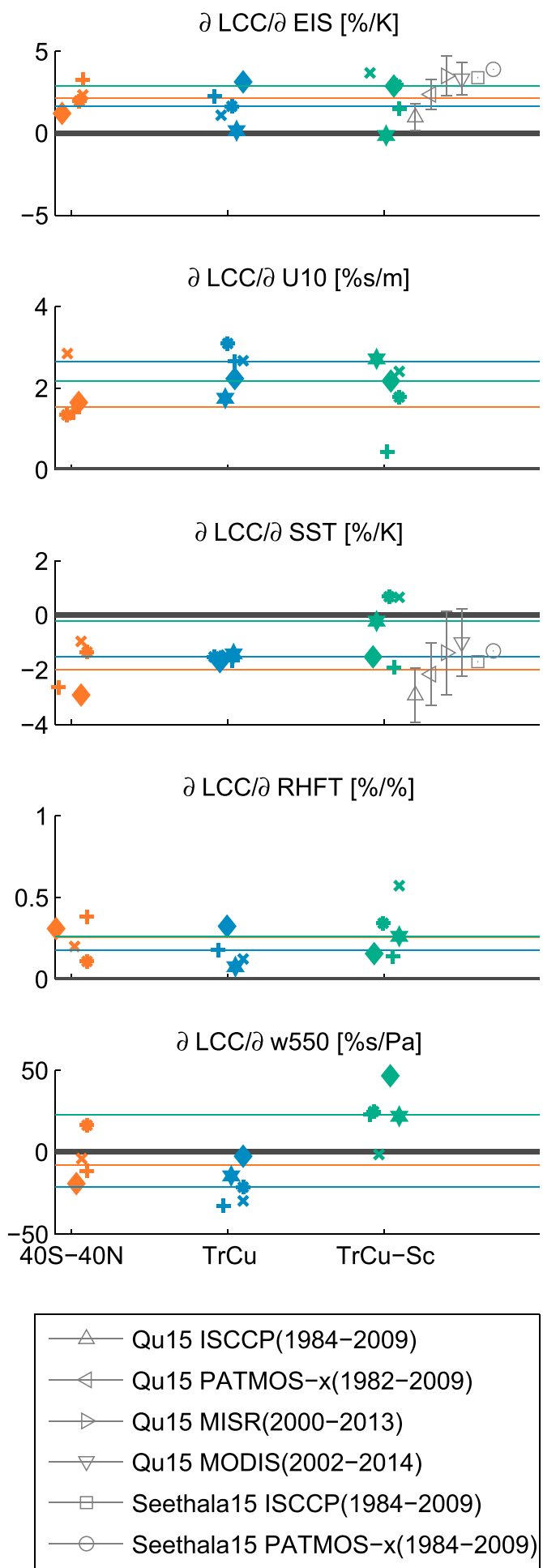

FIG. 4. The coefficients relating LCC to each predictor from the regression models trained in the various study regions. Estimates of coefficient values from the different subregions are shown as in Fig. 2. Horizontal scatter has been added for visual clarity. The region that the regression model was trained in is noted on the $x$ axis. The sensitivity of LCC to EIS and SST calculated in Qu et al. (2015) and Seethala et al. (2015) from interannual and monthly anomalies, respectively, are shown also. The LCC dataset and time range used in each study is noted in the legend. regions of deep convection from spuriously biasing the results.

The regression models predict the observed record of LCC at 8-day temporal resolution with a correlation of greater than 0.4 and an RMSE of $20 \%$ (where $\%$ is units of LCC). When the regression models are evaluated based on their ability to predict the observed climatology of LCC, the correlation between predicted and observed LCC exceeds 0.6 and RMSE is below $15 \%$ (in units of LCC) (Fig. 3). Mean bias is less than 10\% (in units of LCC). Overall, the regression models are able to reproduce some fraction of the variability in octetaveraged LCC and a fairly substantial portion of the climatological LCC.

\section{Results}

\section{a. Coefficients relating predictors to LCC}

We now consider the differences between the regression models created using data from different subregions. The range of the coefficients given by the different regression models relating LCC to each predictor variable is shown in Fig. 4. The coefficient relating EIS and SST to LCC estimated by previous studies is shown for comparison. These studies are Seethala et al. (2015) and Qu et al. (2015). Qu et al. (2015) used interannual anomalies in ISCCP, PATMOS-x, MISR, and MODIS data regionally averaged over five Sc-dominated regimes to create a regression model of LCC on EIS and SST. Seethala et al. (2015) used monthly anomalies in ISCCP and PATMOS-x data at $2.5^{\circ} \times 2.5^{\circ}$ spatial resolution from $\mathrm{Sc}$-dominated regions to create a regression model on SST, SST advection, and EIS.

The coefficients relating U10m and RHFT to LCC are fairly similar across regions. The sign of these coefficients in the regression analysis are in agreement with our a priori expectations. LCC increases with increasing surface wind speed in all regions and datasets. This is consistent with increased fluxes of water into the boundary layer (Bretherton et al. 2013). Increasing RH in the free troposphere increases LCC everywhere, in keeping with expectations (Fig. 4). Increasing subsidence has uncertain effects on LCC and leads to a decrease in LCC only in the $40^{\circ} \mathrm{S}-40^{\circ} \mathrm{N}$ and trade cumulus regions. In the $\mathrm{TrCu}-\mathrm{Sc}$ regions the dependence on subsidence is positive. This is likely due to the dependence of LCC on subsidence changing sign between low- and high-EIS regimes as shown by Myers and Norris (2013), although it is interesting to note that this is the opposite sign found by $\mathrm{Qu}$ et al. (2015) in their analysis of GCM LCC.

The coefficient relating EIS to LCC is positive in every region except the Canarian stratocumulus-dominated region and the North Atlantic trade cumulus (Fig. 4). 
This may reflect the scant cloud cover in these regions relative to the other regions considered in this study rather than some underlying physical difference (Fig. 2). Analysis of the dependence of ship-observed seasonal LCC on EIS, not considering variability in SST, yields values of $6 \%$ (Wood and Bretherton 2006) and $5.3 \% \mathrm{~K}^{-1}$ (Koshiro and Shiotani 2014) in the regions identified in Klein and Hartmann (1993) and 4.7\% K $\mathrm{K}^{-1}$ over the global ocean (Koshiro and Shiotani 2014). These values are larger than the coefficient values relating EIS and LCC yielded by our analysis (Fig. 4). Overall, the coefficient relating EIS to LCC produced from the 8-day MODIS data is within the uncertainty of the coefficient calculated from other remote sensing studies (Qu et al. 2015; Seethala et al. 2015). We have extended this comparison to longer-time-scale studies by repeating our analysis averaging the data to annualmean values, as opposed to 8-day means. This analysis is shown in Fig. S1 of the supplemental material. It was found that the same analysis performed on annual-mean data became somewhat uncertain. EIS sensitivity increased in the regression models trained using data from the $\mathrm{TrCu}$ and global region, while it became highly uncertain in the regression models trained in the $\mathrm{TrCu}-\mathrm{Sc}$ regions. SST sensitivity decreased somewhat and became more uncertain across the $\mathrm{TrCu}-\mathrm{Sc}$ regions. However, this appears to be very sensitive to whether the annual-mean values or the anomalies in the annualmean relative to the long-term mean (as used in previous studies of LCC on longer time scales; Myers and Norris 2015; Qu et al. 2015) were used to train the regression models. We repeated our analysis using anomalies in the annual-mean relative to the long-term mean at every latitude and longitude and found that the coefficients relating SST and EIS to LCC actually became more consistent across regions and were consistent with regression models trained on 8-day averages. This indicates that, consistent with previous studies, these effects are relatively time-scale invariant (Myers and Norris 2016; Qu et al. 2015). However, we did find that the coefficients relating wind speed, subsidence, and RHFT to LCC became more varied depending on the subregion used to train the regression model. Overall, our particular dataset agrees with previous studies of LCC dependence on EIS and SST at longer time scales.

The dependences of LCC on SST in the regression models in the various subsets of the data ( $\mathrm{TrCu}$, etc.) are always negative or are indistinguishable from zero. The coefficient is only positive in some of the models trained in the $\mathrm{TrCu}$-Sc regions. The regression models trained in the $\mathrm{TrCu}-\mathrm{Sc}$ regions produce a wide range of possible coefficient values depending on region where the regression model is trained. Ultimately, only two of the
TrCu-Sc regions show a positive LCC-SST coefficient. The remaining data subsets show a robustly negative LCC-SST coefficient.

A negative dependence of LCC on SST is consistent with numerous LES studies and observational studies (Bretherton and Blossey 2014; Clement et al. 2009; Myers and Norris 2015, 2016; Qu et al. 2015; Seethala et al. 2015). The dependence of LCC on SST agrees qualitatively with previous satellite-based studies at longer temporal scales over the stratocumulus regimes (Qu et al. 2015; Seethala et al. 2015).

\section{b. Estimated changes in LCC for a 1-K increase in SST}

The coefficients derived from the different regional subsets are in general agreement with our expectations based on LES simulation and other observational studies. Because EIS and SST both increase with warming (Qu et al. 2014a; Webb et al. 2013), the change in LCC is sensitive to the relative strength of the dependence of LCC on these predictors. Significant spatial structure exists in the EIS response to warming (Qu et al. 2014a), but for the purpose of this simplified calculation we assume EIS increases by $0.2 \mathrm{~K}$ per $1-\mathrm{K}$ SST increase (Webb et al. 2013). This greatly simplifies the projected global warming response but is useful in terms of evaluating how consistent a picture of change in LCC is given by the regression models trained in this study as compared to previous studies. The change in LCC is calculated as $\Delta \mathrm{LCC}=0.2 \mathrm{~K}(\partial \mathrm{LCC} / \partial \mathrm{EIS})+1 \mathrm{~K}(\partial \mathrm{LCC} / \partial \mathrm{SST})$. The coefficients relating EIS and SST to LCC from each of the 14 regression models trained in this study are then used to predict the change in LCC.

It is debatable whether linearity can be assumed in a warming climate. This appears to be a good assumption in GCMs. Linear regression models of LCC created from the current climate in GCMs can generally explain their change in LCC in a warming climate (Myers and Norris 2016; Qu et al. 2014b, 2015). We cannot validate whether the change in observed LCC in a warming climate is relatively linear, and we must content ourselves with noting that a GCM's LCC appears to have a relatively linear response to warming-induced EIS and SST (Myers and Norris 2016; Qu et al. 2014b, 2015). We find that when annual-mean anomalies in LCC and predictors were used to train the regression model for the data used in this study (see Fig. S1) the predicted change in LCC for a 1-K warming and $0.2-\mathrm{K}$ increase in EIS were similar to the results utilizing regression models trained on 8-day means (Fig. S2 in the supplemental material).

The regression models created in our study show a robust dependence on subsidence, RHFT, and U10m. While robust, the strength of these dependencies is not 
strong enough to substantially affect the change in LCC given the expected change in these predictors across the subtropics. Subtropical free-tropospheric RH is likely to decrease in a warming climate and subsidence should weaken (Bretherton et al. 2013). For an idealized warming scenario subsidence decreases by approximately $2 \% \mathrm{~K}^{-1}$ (Bretherton et al. 2013) $\left(\sim 0.1 \mathrm{hPa} \mathrm{day}^{-1}\right.$ relative to estimates of climatological subsidence from ERA-Interim), wind speed should decrease by $0.6 \% \pm$ $0.61 \% \mathrm{~K}^{-1}$ (Bretherton et al. 2013; Lu and Cai 2009), and free-tropospheric $\mathrm{RH}$ decreases by approximately $0.6 \% \mathrm{~K}^{-1}$ (Bretherton et al. 2013; Richter and Xie 2008) (note that percent is an absolute change in $\mathrm{RH}$, not a percentage change). The coefficients relating LCC to these predictors in the regression models do not appear to be large enough to cause the expected changes in these quantities with warming to contribute very strongly to changes in LCC, compared to the expected LCC responses from changes in EIS or SST (Fig. 4). A $0.6 \%$ decrease in RHFT coupled with the coefficients in Fig. 4 implies a decrease in LCC of $0.14 \% \pm 0.08 \%$ (in units of LCC and not differentiating by region where the regression model was trained). A decrease of $0.6 \%$ relative to the $10-\mathrm{m}$ wind speed from ERA-Interim would translate into a decrease of approximately $0.04 \mathrm{~m} \mathrm{~s}^{-1}$. The mean change in LCC calculated from this decrease in wind speed and the regression models shown in Fig. 4 would be $0.08 \% \pm 0.03 \%$. Changes in subsidence on the order of $0.1 \mathrm{hPa} \mathrm{day}^{-1}$ do not significantly affect LCC $(|\Delta \mathrm{LCC}|<0.01 \%)$. The fairly weak contribution of subsidence, wind speed, and RHFT in a warming climate to changing LCC is consistent with the analysis of cloud-controlling factors in CMIP5 models $(\mathrm{Qu}$ et al. 2015; Zhou et al. 2015) and of observed anomalies in SW CRE (Myers and Norris 2015, 2016).

In agreement with previous studies, we find that EIS and SST changes are responsible for the majority of the change in LCC with warming (Myers and Norris 2015, 2016; Qu et al. 2015; Seethala et al. 2015; Zhou et al. 2015). However, it is worth noting that other factors not considered in this analysis may influence LCC changes in a warming world. Increasing greenhouse gases increase atmospheric emissivity and decrease LCC through suppression of cloud-top radiative cooling (Bretherton et al. 2013). We do not account for this effect, and thus our decrease in LCC is weaker than the decrease in LCC that would occur in a world warmed by greenhouse gases. The decrease in LCC with warming estimated here is discussed in the context of an idealized change over the subtropics as a whole. It is important to note that regional changes in subsidence, wind speed, and free-tropospheric RH may strongly affect changes in LCC in a warming world.
Based on the internal consistency of our analysis and the consistency of our results with previous studies (Myers and Norris 2015, 2016; Qu et al. 2015; Seethala et al. 2015) we present a calculation of the change in LCC in a highly idealized warming scenario (Fig. 5). As discussed above, the change in LCC is calculated using the regression models created in each region and assuming SST increases by $1 \mathrm{~K}$ and EIS increases by $0.2 \mathrm{~K}$ (Webb et al. 2006). This estimate is compared to the decrease in LCC calculated using the EIS and SST dependencies calculated by Qu et al. (2015) and Seethala et al. (2015) coupled with a $1-\mathrm{K}$ SST increase and 0.2-K EIS increase.

The change in LCC predicted by the regression models trained on the 8-day MODIS data is within the range consistent with the regression models created in studies on longer-time-scale data (Fig. 5). The regression models trained using data from the entirety of the $40^{\circ} \mathrm{S}-40^{\circ} \mathrm{N}$ region show a robust decrease in LCC of around $0.5 \%-2.7 \%$. The regression models trained on the trade cumulus-dominated regions are more consistent and predict a decrease of $1 \%-1.4 \%$. The regression models trained on the stratocumulus-dominated regimes predict a change in LCC from $+1.4 \%$ to $-1.6 \%$, depending on which stratocumulus-dominated region is used to train the model. The change in LCC predicted by regression models created by Seethala et al. (2015) and $\mathrm{Qu}$ et al. (2015) ranges in mean value from $-0.34 \%$ to $-2.73 \%$. Qu et al. (2015) used bootstrapping to calculate uncertainty on the coefficients in their regression model. In our study the uncertainty in the coefficients relating EIS and SST to LCC as calculated by Qu et al. (2015) are used to calculate the uncertainty in the change in LCC as $\sigma_{\Delta \mathrm{LCC}}=\left[\left(0.2 \sigma_{\partial \mathrm{LCC} / \partial \mathrm{EIS}}\right)^{2}+\left(\sigma_{\partial \mathrm{LCC} / \partial \mathrm{EIS}}\right)^{2}\right]^{1 / 2}$.

The change in LCC inferred by examining 8-dayaveraged LCC over the trade cumulus regions is robustly negative and highly consistent across regression models trained in each subregion (see Table 2). It is unclear how to interpret the large range in $\Delta \mathrm{LCC}$ predicted by regression models trained in the $\mathrm{TrCu}-\mathrm{Sc}$ regions. It is possible that this uncertainty represents the narrow range of SST values in these regions in the training datasets. The poor consensus as to the dependence of LCC on SST diagnosed by the regression model in the stratocumulus-dominated regions does not appear to translate to the dependence in the regression models trained on both stratocumulus and trade cumulusdominated regions. This seems to be supportive of this effect at least being partially due to relatively low variance in SST in the TrCu-Sc regions. With the exception of a few subsets of data in the $\mathrm{TrCu}-\mathrm{Sc}$ regions, our analysis supports a decrease in LCC across the subtropics with warming. 

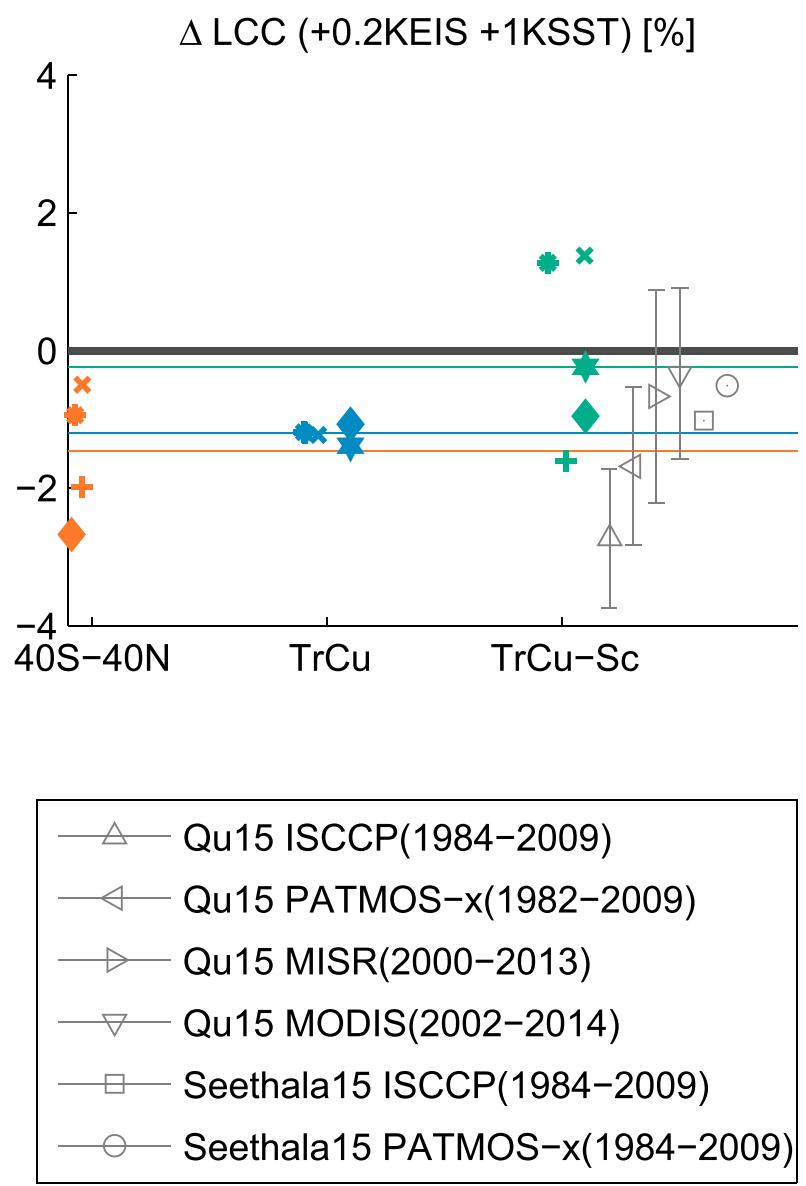

FIG. 5. The change in LCC inferred from a uniform increase in SST of $1 \mathrm{~K}$ accompanied by an increase in EIS of $0.2 \mathrm{~K}$. The coefficients from the regression models shown in Fig. 4 are used to calculate the change in LCC. The region that the regression model was trained in is noted on the $x$ axis. The LCC change calculated using the coefficients of Qu et al. (2015) and Seethala et al. (2015) for EIS $+0.2 \mathrm{~K}$ and SST $+1 \mathrm{~K}$ are also shown. The symbols used for each region correspond to the key in Fig. 2.

\section{Conclusions}

In this study we utilize the 8-day-averaged observations available from the satellite era to study how low cloud cover (LCC) responds to variability in dynamics and thermodynamics. The dataset is subdivided into regions associated with trade cumulus and stratocumulus (Fig. 2 and Table 2). The sensitivity of LCC to thermodynamic and dynamic predictors is evaluated in each subregion using partial least squares linear regression on a set of five predictor variables (Fig. 4 and Table 1). Several robust elements of the LCC response to various predictors emerge across these subsets of observational data. LCC increases with increasing estimated inversion strength (EIS), wind speed, and free-tropospheric RH. Subsidence appears to increase and decrease LCC, depending on regime. Increasing SST decreases LCC, although this dependence is much more uncertain in stratocumulusdominated regions and two of the stratocumulusdominated regions show SST increasing LCC. Overall, the dependence of LCC on the predictor variables shown in this study largely confirm a priori expectations from large-eddy simulations and previous observational studies utilizing different datasets and longer time scales (Blossey et al. 2013; Bretherton and Blossey 2014; Bretherton et al. 2013; Myers and Norris 2013, 2015; Qu et al. 2015; Seethala et al. 2015).

In a warming world both EIS and SST increase $(\mathrm{Qu}$ et al. 2014a). Whether LCC increases or decreases with warming depends on the relative contributions of these terms. We estimate the LCC change consistent with a 1-K surface warming and a $0.2-\mathrm{K}$ increase in EIS based on the regression models trained in this study. Overall, the inferred $\triangle \mathrm{LCC}$ from the regression models trained in the stratocumulus-dominated regions is very uncertain and LCC was inferred to change between $+1.4 \%$ and $-1.6 \%$. This uncertainty may be partially due to the high degree of correlation between SST and EIS (Fig. 1) and the relatively narrow range of SSTs available to train the regression model in each of the stratocumulus-dominated regions. While our analysis of the stratocumulusdominated regions is inconclusive as to whether LCC would increase or decrease with warming, training the regression model on $20^{\circ}$-latitude-band subsets of the data containing both the stratocumulus-dominated and $\mathrm{TrCu}-$ dominated regions indicates a robust decrease in LCC with warming. The regression models trained in these regions show that increasing SST always decreases LCC and indicate a warming-induced decrease in LCC of $0.5 \%-2.7 \%$. If the regression model is restricted to $\mathrm{TrCu}-$ dominated regions, a decrease of $1 \%-1.4 \%$ is predicted. If the regression models created by Seethala et al. (2015) and Qu et al. (2015) are used to infer the change in LCC using the method in this study, they predict a decrease of $0.3 \%-2.7 \%$, depending on the observational dataset used. This result is consistent with the decrease predicted by this study. Overall, the range of changes in LCC per unit of surface warming indicated by observed relationships in this study and past studies is substantially smaller than the range inferred from the sensitivity of GCM LCC to EIS and SST deduced by Qu et al. (2015). If the sensitivity of LCC to EIS and SST in the GCMs examined by Qu et al. (2015) are used to calculate the change in LCC resulting from a $1-\mathrm{K}$ increase in SST and a $0.2-\mathrm{K}$ increase in EIS the change is between $-2.7 \%$ and $+1.7 \%$.

In summary, examination of the variability of 8-day means in trade cumulus regions robustly predicts that LCC should decrease by $1 \%-1.4 \%$ for an idealized $1-\mathrm{K}$ warming, while data from stratocumulus-dominated regions do 
not indicate a robust response of $\mathrm{LCC}$ to warming. The robust decrease in LCC inferred for $\mathrm{TrCu}$-dominated regions, in combination with the robust decrease in LCC inferred by studies utilizing longer-time-scale observations over the stratocumulus-dominated regions (Qu et al. 2015; Seethala et al. 2015), suggests that GCMs that increase LCC with warming are not consistent with the observed variability of LCC in the current climate.

Acknowledgments. The authors thank Peter Blossey, Christopher Bretherton, and Xin Qu for their guidance. The authors also wish to thank Xin Qu for graciously providing data from Qu et al. (2015). Finally, the authors wish to thank Steve Klein for editing this article and three anonymous reviewers for their help and advice. D.T.M. and D.L.H. were supported under NASA Grant NNX14AG26G. R.E. and R.W. were supported under NASA Grant NNXBAQ35G.

\section{REFERENCES}

Albrecht, B. A., 1989: Aerosols, cloud microphysics, and fractional cloudiness. Science, 245, 1227-1230, doi:10.1126/ science.245.4923.1227.

Aumann, H. H., and Coauthors, 2003: AIRS/AMSU/HSB on the Aqua mission: Design, science objectives, data products, and processing systems. IEEE Trans. Geosci. Remote Sens., 41, 253-264, doi:10.1109/TGRS.2002.808356.

Blossey, P. N., and Coauthors, 2013: Marine low cloud sensitivity to an idealized climate change: The CGILS LES intercomparison. J. Adv. Model. Earth Syst., 5, 234-258, doi:10.1002/jame.20025.

Bony, S., and Coauthors, 2006: How well do we understand and evaluate climate change feedback processes? J. Climate, 19, 3445-3482, doi:10.1175/JCLI3819.1.

Bretherton, C. S., and P. N. Blossey, 2014: Low cloud reduction in a greenhouse-warmed climate: Results from Lagrangian LES of a subtropical marine cloudiness transition. J. Adv. Model. Earth Syst., 6, 91-114, doi:10.1002/2013MS000250.

,-- , and C. R. Jones, 2013: Mechanisms of marine low cloud sensitivity to idealized climate perturbations: A single-LES exploration extending the CGILS cases. J. Adv. Model. Earth Syst., 5, 316-337, doi:10.1002/jame.20019.

Brient, F., and S. Bony, 2013: Interpretation of the positive low-cloud feedback predicted by a climate model under global warming. Climate Dyn., 40, 2415-2431, doi:10.1007/s00382-011-1279-7.

Caldwell, P. M., Y. Y. Zhang, and S. A. Klein, 2013: CMIP3 subtropical stratocumulus cloud feedback interpreted through a mixed-layer model. J. Climate, 26, 1607-1625, doi:10.1175/ JCLI-D-12-00188.1.

Clement, A. C., R. Burgman, and J. R. Norris, 2009: Observational and model evidence for positive low-level cloud feedback Science, 325, 460-464, doi:10.1126/science.1171255.

Dee, D. P., and Coauthors, 2011: The ERA-Interim reanalysis: Configuration and performance of the data assimilation system. Quart. J. Roy. Meteor. Soc., 137, 553-597, doi:10.1002/ qj. 828 .

de Jong, S., 1993: SIMPLS: An alternative approach to partial least squares regression. Chemom. Intell. Lab. Syst., 18, 251-263, doi:10.1016/0169-7439(93)85002-X. de Roode, S. R., A. P. Siebesma, S. dal Gesso, H. J. J. Jonker, J. Schalkwijk, and J. Sival, 2014: A mixed-layer model study of the stratocumulus response to changes in large-scale conditions. J. Adv. Model. Earth Syst., 6, 1256-1270, doi:10.1002/ 2014MS000347.

Eastman, R., and R. Wood, 2016: Factors controlling low-cloud evolution over the eastern subtropical oceans: A Lagrangian perspective using the A-Train satellites. J. Atmos. Sci., 73, 331-351, doi:10.1175/JAS-D-15-0193.1.

_ , S. G. Warren, and C. J. Hahn, 2011: Variations in cloud cover and cloud types over the ocean from surface observations, 1954-2008. J. Climate, 24, 5914-5934, doi:10.1175/ 2011JCLI3972.1.

_, R. Wood, and C. S. Bretherton, 2016: Time scales of clouds and cloud-controlling variables in subtropical stratocumulus from a Lagrangian perspective. J. Atmos. Sci., 73, 3079-3091, doi:10.1175/JAS-D-16-0050.1.

Hartmann, D. L., and D. A. Short, 1980: On the use of Earth radiation budget statistics for studies of clouds and climate. J. Atmos. Sci., 37, 1233-1250, doi:10.1175/1520-0469(1980)037<1233: OTUOER $>2.0 . \mathrm{CO} ; 2$

Held, I. M., and B. J. Soden, 2000: Water vapor feedback and global warming. Annu. Rev. Energy Environ., 25, 441-475, doi:10.1146/ annurev.energy.25.1.441.

Jones, C. R., C. S. Bretherton, and P. N. Blossey, 2014: Fast stratocumulus time scale in mixed layer model and large eddy simulation. J. Adv. Model. Earth Syst., 6, 206-222, doi:10.1002/ 2013MS000289.

Klein, S. A., and D. L. Hartmann, 1993: The seasonal cycle of low stratiform clouds. J. Climate, 6, 1587-1606, doi:10.1175/ 1520-0442(1993)006<1587:TSCOLS > 2.0.CO;2.

- — - and J. R. Norris, 1995: On the relationships among low-cloud structure, sea surface temperature, and atmospheric circulation in the summertime northeast Pacific. J. Climate, 8, 1140-1155, doi:10.1175/1520-0442(1995)008<1140: OTRALC $>2.0 . \mathrm{CO} ; 2$

Koshiro, T., and M. Shiotani, 2014: Relationship between low stratiform cloud amount and estimated inversion strength in the lower troposphere over the global ocean in terms of cloud types. J. Meteor. Soc. Japan, 92, 107-120, doi:10.2151/jmsj.2014-107.

Kubar, T. L., D. E. Waliser, J. L. Li, and X. Jiang, 2012: On the annual cycle, variability, and correlations of oceanic lowtopped clouds with large-scale circulation using Aqua MODIS and ERA-Interim. J. Climate, 25, 6152-6174, doi:10.1175/JCLI-D-11-00478.1.

Li, J., J. Huang, K. Stamnes, T. Wang, Q. Lv, and H. Jin, 2015: A global survey of cloud overlap based on CALIPSO and CloudSat measurements. Atmos. Chem. Phys., 15, 519-536, doi:10.5194/acp-15-519-2015.

Lu, J., and M. Cai, 2009: Stabilization of the atmospheric boundary layer and the muted global hydrological cycle response to global warming. J. Hydrometeor., 10, 347-352, doi:10.1175/ 2008JHM1058.1.

Maddux, B. C., S. A. Ackerman, and S. Platnick, 2010: Viewing geometry dependencies in MODIS cloud products. J. Atmos. Oceanic Technol., 27, 1519-1528, doi:10.1175/2010JTECHA1432.1.

Mauger, G. S., and J. R. Norris, 2010: Assessing the impact of meteorological history on subtropical cloud fraction. J. Climate, 23, 2926-2940, doi:10.1175/2010JCLI3272.1.

McCoy, D. T., D. L. Hartmann, and D. P. Grosvenor, 2014: Observed Southern Ocean cloud properties and shortwave reflection. Part I: Calculation of SW flux from observed cloud properties. J. Climate, 27, 8836-8857, doi:10.1175/JCLI-D-14-00287.1. 
Myers, T. A., and J. R. Norris, 2013: Observational evidence that enhanced subsidence reduces subtropical marine boundary layer cloudiness. J. Climate, 26, 7507-7524, doi:10.1175/ JCLI-D-12-00736.1.

$\longrightarrow$, and — 2015: On the relationships between subtropical clouds and meteorology in observations and CMIP3 and CMIP5 models. J. Climate, 28, 2945-2967, doi:10.1175/JCLI-D-14-00475.1.

— and - 2016: Reducing the uncertainty in subtropical cloud feedback. Geophys. Res. Lett., 43, 2144-2148, doi:10.1002/ 2015 GL067416.

Nakajima, T., A. Higurashi, K. Kawamoto, and J. E. Penner, 2001: A possible correlation between satellite-derived cloud and aerosol microphysical parameters. Geophys. Res. Lett., 28, 1171-1174, doi:10.1029/2000GL012186.

Norris, J. R., and C. B. Leovy, 1994: Interannual variability in stratiform cloudiness and sea surface temperature. J. Climate, 7, 19151925, doi:10.1175/1520-0442(1994)007<1915:IVISCA > 2.0.CO;2.

—, R. J. Allen, A. T. Evan, M. D. Zelinka, C. W. O'Dell, and S. A. Klein, 2016: Evidence for climate change in the satellite cloud record. Nature, 536, 72-75, doi:10.1038/nature18273.

Oreopoulos, L., 2005: The impact of subsampling on MODIS level3 statistics of cloud optical thickness and effective radius. IEEE Trans. Geosci. Remote Sens., 43, 366-373, doi:10.1109/ TGRS.2004.841247.

Platnick, S., M. D. King, S. A. Ackerman, W. P. Menzel, B. A. Baum, J. C. Riedi, and R. A. Frey, 2003: The MODIS cloud products: Algorithms and examples from Terra. IEEE Trans. Geosci. Remote Sens., 41, 459-473, doi:10.1109/TGRS.2002.808301.

Qu, X., A. Hall, S. Klein, and P. Caldwell, 2014a: The strength of the tropical inversion and its response to climate change in 18 CMIP5 models. Climate Dyn., 45, 375-396, doi:10.1007/ s00382-014-2441-9.

and $-2014 \mathrm{~b}$ : On the spread of changes in marine low cloud cover in climate model simulations of the 21st century. Climate Dyn., 42, 2603-2626, doi:10.1007/s00382-013-1945-z.

$-, \ldots,-$, and A. DeAngelis, 2015: Positive tropical marine low-cloud cover feedback inferred from cloud-controlling factors. Geophys. Res. Lett., 42, 7767-7775, doi:10.1002/ 2015 GL065627.

Quaas, J., 2012: Evaluating the "critical relative humidity" as a measure of subgrid-scale variability of humidity in general circulation model cloud cover parameterizations using satellite data. J. Geophys. Res., 117, D09208, doi:10.1029/2012JD017495.

Randall, D. A., 1984: Stratocumulus cloud deepening through entrainment. Tellus, 36A, 446-457, doi:10.1111/j.1600-0870.1984.tb00261.x.

Richter, I., and S.-P. Xie, 2008: Muted precipitation increase in global warming simulations: A surface evaporation perspective. J. Geophys. Res., 113, D24118, doi:10.1029/2008JD010561.

Rieck, M., L. Nuijens, and B. Stevens, 2012: Marine boundary layer cloud feedbacks in a constant relative humidity atmosphere. J. Atmos. Sci., 69, 2538-2550, doi:10.1175/JAS-D-11-0203.1.

Schneider, S. H., 1972: Cloudiness as a global climatic feedback mechanism: The effects on the radiation balance and surface temperature of variations in cloudiness. J. Atmos. Sci., 29, 14131422, doi:10.1175/1520-0469(1972)029<1413:CAAGCF > 2.0.CO;2.

Seethala, C., J. R. Norris, and T. A. Myers, 2015: How has subtropical stratocumulus and associated meteorology changed since the 1980s? J. Climate, 28, 8396-8410, doi:10.1175/ JCLI-D-15-0120.1.

Susskind, J., C. D. Barnet, and J. M. Blaisdell, 2003: Retrieval of atmospheric and surface parameters from AIRS/AMSU/HSB data in the presence of clouds. IEEE Trans. Geosci. Remote Sens., 41, 390-409, doi:10.1109/TGRS.2002.808236.

_ _ J. M. Blaisdell, and L. Iredell, 2014: Improved methodology for surface and atmospheric soundings, error estimates, and quality control procedures: the atmospheric infrared sounder science team version-6 retrieval algorithm. J. Appl. Remote Sens., 8, 084994, doi:10.1117/1.JRS.8.084994.

van der Dussen, J. J., S. R. de Roode, S. D. Gesso, and A. P. Siebesma, 2015: An LES model study of the influence of the free tropospheric thermodynamic conditions on the stratocumulus response to a climate perturbation. J. Adv. Model. Earth Syst., 7, 670-691, doi:10.1002/2014MS000380.

Vial, J., J. L. Dufresne, and S. Bony, 2013: On the interpretation of inter-model spread in CMIP5 climate sensitivity estimates. Climate Dyn., 41, 3339-3362, doi:10.1007/s00382-013-1725-9.

Webb, M. J., and Coauthors, 2006: On the contribution of local feedback mechanisms to the range of climate sensitivity in two GCM ensembles. Climate Dyn., 27, 17-38, doi:10.1007/s00382-006-0111-2.

_ F. Lambert, and J. M. Gregory, 2013: Origins of differences in climate sensitivity, forcing and feedback in climate models. Climate Dyn., 40, 677-707, doi:10.1007/s00382-012-1336-x.

Wold, S., A. Ruhe, H. Wold, and I. W. Dunn, 1984: The collinearity problem in linear regression. The partial least squares (PLS) approach to generalized inverses. SIAM J. Sci. Stat. Comput., 5, 735-743, doi:10.1137/0905052.

—, M. Sjöström, and L. Eriksson, 2001: PLS-regression: A basic tool of chemometrics. Chemom. Intell. Lab. Syst., 58, 109-130, doi:10.1016/S0169-7439(01)00155-1.

Wood, R., 2007: Cancellation of aerosol indirect effects in marine stratocumulus through cloud thinning. J. Atmos. Sci., 64, 26572669, doi:10.1175/JAS3942.1.

_ 2012: Stratocumulus clouds. Mon. Wea. Rev., 140, 2373-2423, doi:10.1175/MWR-D-11-00121.1.

— stratiform low cloud cover and lower-tropospheric stability. J. Climate, 19, 6425-6432, doi:10.1175/JCLI3988.1.

Yue, Q., B. H. Kahn, H. Xiao, M. M. Schreier, E. J. Fetzer, J. Teixeira, and K. Sušelj, 2013: Transitions of cloud-topped marine boundary layers characterized by AIRS, MODIS, and a large eddy simulation model. J. Geophys. Res. Atmos., 118, 8598-8611, doi:10.1002/jgrd.50676.

Zelinka, M. D., S. A. Klein, and D. L. Hartmann, 2012: Computing and partitioning cloud feedbacks using cloud property histograms. Part II: Attribution to changes in cloud amount, altitude, and optical depth. J. Climate, 25, 3736-3754, doi:10.1175/ JCLI-D-11-00249.1.

K. E. Taylor, T. Andrews, M. J. Webb, J. M. Gregory, and P. M. Forster, 2013: Contributions of different cloud types to feedbacks and rapid adjustments in CMIP5. J. Climate, 26, 5007-5027, doi:10.1175/JCLI-D-12-00555.1.

Zhou, C., M. D. Zelinka, A. E. Dessler, and S. A. Klein, 2015: The relationship between interannual and long-term cloud feedbacks. Geophys. Res. Lett., 42, 10 463-10 469, doi:10.1002/2015GL066698. 